\title{
Chlamydial infection
}

\section{Isolation of Chlamydia from patients with non-specific genital infection}

\author{
J. D. ORIEL, P. REEVE, P. POWIS, A. MILlER, AND C. S. NICOL \\ Department of Venereal Diseases, St. Thomas' Hospital, London
}

The aetiology of non-specifis genital infection continues to excite widespread interest. When the specific causes of non-gonococcal urethritis in men (trichomonal, candidal, and herpetic infections, mechanical irritants, and bacterial infection secondary to disease elsewhere in the genito-urinary tract) have been excluded, there remains a large number of men with 'non-specific' urethritis (NSU) for which no cause can be identified by conventional methods. There are epidemiological reasons for regarding NSU as a sexually transmissible disease (Boyd, Csonka, and Oates, 1958), and because of this it is assumed that the causative agent, or agents, may also infect the female genital tract, although the clinical features of such infection cannot be described with any certainty.

In recent years, evidence has accumulated that organisms of the Chlamydia group may be responsible for some cases of non-specific genital infection. The presence of Chlamydia in the genital tract in association with chlamydial eye infection is now well authenticated. T'ang, Chang, Huang, and Wang (1957) had shown that Chlamydia could be recovered from patients with trachoma by a yolk-sac inoculation technique; by means of the same method, Chlamydia were recovered from the genital tracts of the parents of some babies with neonatal chlamydial eye infections, and these observations were later extended to include adults with chlamydial ocular disease, who likewise showed evidence of chlamydial genital infection (Jones, Collier, and Smith, 1959; Dunlop, Jones, and Al-Hussaini, 1964; Dunlop, Freedman, Garland, Harper, Jones, Race, du Toit, and Treharne, 1967). Since some of the men yielding Chlamydia isolates from the urethra showed clinical evidence of NSU, it was clearly of interest to investigate the possibility that Chlamydia isolates could be obtained from men with NSU which was not associated with ocular infection.

Dunlop and others (1967), using the yolk-sac

Received for publication June 19, 1972 technique, obtained Chlamydia isolates from nineteen out of 89 unselected cases of NSU and from fourteen out of forty female contracts of these men. However, Ford and McCandlish (1969), also using the yolk-sac technique, recovered Chlamydia from only fifteen out of 133 men with NSU. An improved method for isolating Chlamydia was developed by Gordon and Quan (1965), who found that centrifugation of specimens on to irradiated McCoy cells for culture was more sensitive than culture in yolk sacs (Gordon, Dressler, and Quan, 1967; Gordon, Harper, Quan, Treharne, Dwyer, and Garland, 1969). Using a simplified version of this technique (Darougar, Kinnison, and Jones, 1971), Dunlop, Hare, Darougar, and Jones (1971) reported the isolation of Chlamydia from eighteen out of 41 men with NSU. When 21 female contacts of these men were examined, Chlamydia was isolated from five, all of whom were contacts of men who had yielded positive isolates.

Whether chlamydial infection is a major cause of NSU cannot at present be decided with certainty. Other organisms have been recovered from the genital tracts of men with NSU and their contacts whose pathogenicity is now in doubt, notably the T-strain mycoplasma (Black and Rasmussen, 1968; Hare, Dunlop, and Taylor-Robinson, 1969). On present evidence, the possibility exists that, although there is a genital reservoir of chlamydial infection, the organisms are pathogenic only to the eye, and that Chlamydia is only associated with non-specific genital infection and does not cause it.

Investigations into the role of Chlamydia in the aetiology of NSU have not hitherto been controlled by studying the incidence of chlamydial infection in sexually active men who have no demonstrable urethritis. Moreover, further study of sexual contacts of men with NSU might indicate whether women with positive isolates were primary or secondary contacts of men with chlamydial genital infection, and the sexual infectivity of the organisms could then be assessed.

We are reporting here the results of investigations 
into the isolation of Chlamydia from:

(1) A group of unselected men with first attacks of NSU,

(2) Female contacts of these men,

(3) A control group of men with no evidence of urethritis.

\section{Material and methods}

\section{PATIENTS}

\section{(1) Men with NSU}

Men were included in this study if:

(a) They were heterosexual;

(b) There was evidence of urethritis as shown by the presence of a minimum of 10 polymorphonuclear leucocytes per high-power field (using a $\times 100$ objective) in a urethral smear;

(c) There was no clinical evidence of herpes, no intrameatal warts, and no microbiological evidence of gonococcal, trichomonal, or candidal infection;

(d) There was no past history of urethritis, gonococcal or non-gonococcal;

(e) No antibiotics had been taken during the 2 months before examination.

\section{(2) Control men}

These were heterosexual patients who gave no history of urethritis and whose urethral smears, collected early in the morning after they had held urine overnight, showed no polymorphonuclear leucocytes and whose subsequent first and second urine specimens were clear.

\section{(3) Women}

These were sexual contacts of men in Group 1.

\section{SPECIMENS}

(1) Men with NSU

Specimen collection was carried out not less than 2 hours after micturition; in 29 cases it was performed in the early morning before the patient had passed urine. Urethral specimens for routine examination were taken with a wire loop; a wet and a dry slide were prepared and culture media inoculated (see below) to establish the diagnosis and exclude other genital infections.

The patient then passed urine into two glasses, after which tests for Chlamydia were done. The method used was that described by Dunlop and others (1964) and Dunlop, Hare, Darougar, Jones, and Rice (1969). The glans penis was cleaned with saline and dried. $1 \mathrm{ml}$. of 0.5 per cent. lignocaine solution was instilled into the urethra with a serum syringe, and allowed to run away after 2 minutes. A Jones-Dunlop urethral curette (manufactured by Down Bros. and Mayer and Phelps Ltd., London) was next passed as far as the urethral bulb four times, and urethral scrapings from each quadrant were transferred to $2 \mathrm{ml}$. of cell culture medium (see below) in a small screw-capped bottle.
In a second series of patients, urethral specimens for Chlamydia isolation were collected at least 2 hours after the patient had passed urine. A cotton-wool swab sterilized by irradiation was introduced into the distal urethra before other specimens were obtained; the end of the swab was then broken into a bottle of cell culture medium.

\section{(2) Control men}

Urethral specimens were collected as for Group 1; material for Chlamydia isolation was again taken with a curette after micturition.

\section{(3) Women}

Specimens were collected with the patient in the lithotomy position. The vulva was cleaned with cotton-wool and a Cusco speculum inserted. First, a wet and a dry vaginal slide, and vaginal material for culture for $T$. vaginalis and for $C$. albicans were taken. Then the cervix was inspected and a specimen for cytology taken with an Ayre spatula. After the cervix had been cleaned with a cotton-wool swab, a specimen for Chlamydia culture was collected by inserting a cotton-wool swab deeply into the cervical canal and rotating it against the walls; it was then broken into a bottle of cell culture medium. Cervical material was next inoculated on to a culture plate for gonococci, and a final specimen smeared on a slide. The speculum was now withdrawn, and with cotton-wool swabs urethral specimens were collected for Chlamydia and $N$. gonorrhoeae cultures, and a final specimen smeared on a slide. Rectal examination was not carried out.

In both men and women, a general medical examination was performed and blood was taken for serological tests for syphilis and chlamydial antibodies.

\section{MICROBIOLOGICAL EXAMINATIONS}

(1) Tests for N. gonorrhoeae: T. vaginalis, and C. albicans Urethral slides from men, and urethral, cervical, and vaginal slides from women, were stained by Gram's method and examined for $N$. gonorrhoeae and C. albicans. Gonococcal cultures were performed on modified ThayerMartin medium (Phillips, Humphrey, Middleton, and Nicol, 1972). Wet preparations in a drop of normal saline were examined immediately for $T$. vaginalis. Urethral material from the men was cultured in FeinbergWhittington medium, but this procedure was omitted after the first thirty specimens had yielded negative results. Similarly urethral cultures for $C$. albicans on Sabouraud's medium were taken initially, but were also discontinued after thirty negative results. For women, however, cultures for $T$. vaginalis and $C$. albicans were performed in all cases.

\section{(2) Tests for Chlamydia}

Specimens were collected in $2 \mathrm{ml}$. of cell culture medium containing additional glucose and antibiotics (see below) and kept at $+4^{\circ} \mathrm{C}$. until the cell cultures were inoculated. If inoculation could not be done on the same day as collection, then an equal volume of $0.4 \mathrm{M}$. sucrose/ 
phosphate buffer (Gordon and others, 1969) was added and the specimen stored at $-70^{\circ} \mathrm{C}$.

\section{Cells}

McCoy cells were grown in plastic flasks (Falcon Plastics Ltd.) and, when confluent, were subjected to $6,000 \mathrm{r}$ of $x$-irradiation ( $1 \mathrm{~mm}$. Cu H.V.D.) given over 11 minutes. 5 to 7 days later the cells were suspended, counted, and diluted to $10^{5}$ cells $/ \mathrm{ml}$., and $1 \mathrm{ml}$. was added to each flat-bottomed plastic tube containing a $13 \mathrm{~mm}$. diameter coverslip. 2 days later the cells had spread out and the tubes viere ready for use.

Cell culture medium

Eagle's M.E.M.

Foetal bovine serum

Sodium bicarbonate

Glutamine (30 mg./ml.)

Vitamins (M.E.M. Vits. Flow Labs.)

Streptomycin (1,000 $\mathrm{kg} . / \mathrm{ml}$.)

Per cent.

10

10

$1 \cdot 0$

$1 \cdot 0$

$1 \cdot 0$

When used for inoculations this medium was supplemented with glucose, to a final concentration of $0.03 \mathrm{M}$, and Fungizone (Amphotericin B), to a final concentration of 15.6 i.u. $/ \mathrm{ml}$.

\section{Isolation technique}

The technique used was based on the modification by Darougar and others (1971) of the system used by Gordon and others (1969). Specimens were shaken on a Whirlimixer for $1 \mathrm{~min}$. before being inoculated into tubes, and frozen specimens were first diluted 1:5 with culture medium to avoid damage to the cells by the high sucrose concentration. Aliquots of each specimen were added to three tubes from which the culture medium had been removed, and the tubes were spun for $1 \mathrm{hr}$ at 3,000 r.p.m. $(1,500 \mathrm{G}$.) in an MSE Minor centrifuge, the final temperature of the specimens after centrifugation being $32^{\circ} \mathrm{C}$. Incubation was performed at $35^{\circ} \mathrm{C} .: 1 \mathrm{hr}$ after centrifugation an additional $1 \mathrm{ml}$. medium + glucose was added to each tube and incubation was continued at $35^{\circ} \mathrm{C}$. If the specimen had been frozen, then the medium was removed after $1 \mathrm{hr}$ and replaced with fresh medium.

After approximately 48 hrs' incubation, the medium was removed from two tubes and the cells fixed for 10 min. in methyl alcohol. One tube was then stained with Lugol's iodine and the other with Giemsa's stain. The stained coverslips were mounted on slides and examined for inclusion bodies using a Gillett and Sibert Conference microscope with an $\times 16$ objective for iodine-stained slides, and an $\times 40$ objective with dark-field illumination for Giemsa-stained slides.

The third tube was used for passage, the cells being scraped off the coverslip and the resulting suspension being treated in the same way as the original specimen.

All manipulations were carried out in a Microflow Safety Cabinet fitted with a UV light. A control tube containing sterile culture medium was included with each specimen.

After investigation of about seventy patients, the isolation technique was modified. In only one case were inclusion bodies seen on passage when they had not been detected at the primary isolation attempt; this step was therefore omitted from further investigations. In addition, since no inclusions were seen in the Giemsa-stained coverslips which were not detected by iodine staining, staining by Giemsa's method was omitted.

\section{Results}

(1) Men with NSU

150 heterosexual men who had NSU, apparently for the first time, were studied. 116 were Caucasian, 29 Negro, and five Asian. Their age distribution is shown in Table $I$, the maximum incidence of the disease being between the ages of 21 and 25 years. The youngest patient was aged 16 and the oldest 58 years.

TABLE· I Age distribution of 150 patients with first attacks of NSU

\begin{tabular}{ll}
\hline Age $(y r s)$ & No. of patients \\
\hline $16-20$ & 26 \\
$21-25$ & 49 \\
$26-30$ & 29 \\
$31-35$ & 19 \\
$36-40$ & 14 \\
$41-45$ & 7 \\
46 and over & 6 \\
\hline
\end{tabular}

The commonest symptom was uret'ral discharge, with or without dysuria or urethral irritation; a few patients complained of frequency of micturition. Sixteen patients had no symptoms, but had requested a routine examination. In every case, gonococcal, trichomonal, and candidal infections had been excluded as already described, and none of the patients had genital herpes or intrameatal warts. No patient had conjunctivitis or gave a history of recent eye infection.

Urethral specimens were taken from 105 of the men with a curette and from the remaining 45 with a swab. After inoculation of the specimens onto irradiated $\mathrm{McCoy}$ cells, the following results were obtained:

URETHRAL CURETTINGS

No. of specimens taken $\quad 105$

No. giving Chlamydia isolates

No. giving no isolates

No. of specimens contaminated

35

Isolation rate

in uncontaminated specimens

63
7

36 per cent.

URETHRAL SWABS

No. of specimens taken

No. giving Chlamydia isolates

No. giving no isolates

No. of specimens contaminated

Isolation rate in uncontaminated specimens 
Patients with NSU yielding positive Chlamydia isolates were compared with those who were negative, in respect of race, type of contact admitted, incubation period, and characteristics of urethral discharge. In Table II, Chlamydia isolation is classified according to the race of the patient. It does not appear that the race of the patient with NSU affects the likelihood of chlamydial infection.

TABLE II Isolation of Chlamydia in NSU according to race

\begin{tabular}{|c|c|c|c|c|}
\hline \multirow[b]{3}{*}{ Race } & \multicolumn{4}{|c|}{ Isolation of Chlamydia } \\
\hline & \multicolumn{2}{|l|}{ Positive } & \multicolumn{2}{|l|}{ Negative } \\
\hline & $\begin{array}{l}\text { No. of } \\
\text { Patients }\end{array}$ & per cent. & $\begin{array}{l}\text { No. of } \\
\text { Patients }\end{array}$ & per cent. \\
\hline Caucasian & 37 & 75 & 67 & 78 \\
\hline Negro & 11 & 23 & 16 & 18 \\
\hline Asian & 1 & 2 & 3 & 4 \\
\hline Total & 49 & & 86 & \\
\hline
\end{tabular}

All the patients except one said that they had had intercourse during the 3 months before their symptoms began or, in the case of those with no symptoms, before they first attended. The types of contact admitted were:

(1) Wife only;

(2) Regular girl friend only;

(3) One or more new contacts during the 3-month period, sometimes in addition to wife or regular girl friend,

(4) None.

In Table III, the type of contact is related to positive and negative Chlamydia isolation.

There does not appear to be any difference between the two groups in the type of sexual contact admitted.

The incubation period of the NSU was assessed when possible, although in the patients with no symptoms and those with multiple contacts, this could not be done. The results are shown in Table IV.

TABLE IV Incubation periods of Chlamydiapositive and Chlamydia-negative NSU

\begin{tabular}{lll}
\hline & Isolation of Chlamydia \\
\cline { 2 - 3 } Incubation period & Positive & Negative \\
\cline { 2 - 3 } 1 & 1 & 4 \\
2 & 0 & 4 \\
3 & 1 & 2 \\
4 & 1 & 1 \\
5 & 1 & 0 \\
6 & 0 & 1 \\
7 & 2 & 3 \\
8 & 1 & 1 \\
9 & 1 & 1 \\
10 & 1 & 1 \\
11 & 0 & 0 \\
12 & 1 & 1 \\
13 & 0 & 3 \\
14 & 1 & 2 \\
15 & 2 & 0 \\
16 & 1 & 2 \\
17 & 0 & 2 \\
18 & 1 & 1 \\
19 & 1 & 1 \\
20 & 1 & 0 \\
21 & 2 & 0 \\
$22-28$ & 1 & 2 \\
$29-35$ & 2 & 1 \\
$36-42$ & 1 & 2 \\
\hline
\end{tabular}

The mean incubation period was 16 days in the case of those giving positive Chlamydia isolates, and 12 days in those giving negative results; the difference is probably not significant.

Finally, the type of urethral discharge present in the two groups is compared in Table V. Using the classification of Boyd and others (1958), the discharge was assessed as slight, moderate, or profuse in amount, and as clear, white, or yellow in colour. Again, in respect of the type of urethral discharge found, there is no significant difference between those giving positive and those giving negative Chlamydia isolates.

(2) Control men

Urethral specimens were examined from 34 men with

TABLE III Isolation of Chlamydia in NSU according to type of sexual contact

\begin{tabular}{|c|c|c|c|c|}
\hline \multirow[b]{3}{*}{ Type of contact admitted } & \multicolumn{4}{|c|}{ Isolation of Chlamydia } \\
\hline & \multicolumn{2}{|c|}{ Positive } & \multicolumn{2}{|c|}{ Negative } \\
\hline & No. & per cent. & No. & per cent. \\
\hline Wife only & 2 & 4 & 7 & 8 \\
\hline One regular girl friend only & 7 & 14 & 12 & 14 \\
\hline One or more new contacts & 40 & 82 & 66 & 77 \\
\hline None & 0 & 0 & 1 & 1 \\
\hline Total & 49 & & 86 & \\
\hline
\end{tabular}


TABLE V Characteristics of urethral discharge found on first examination of patients with NSU

\begin{tabular}{|c|c|c|c|c|c|}
\hline \multirow{2}{*}{\multicolumn{2}{|c|}{ Urethral discharge }} & \multicolumn{4}{|c|}{ Isolation of Chlamydia } \\
\hline & & No. of patients & per cint. & No. of patients & per cent. \\
\hline Amount & $\begin{array}{l}\text { None } \\
\text { Slight } \\
\text { Moderate } \\
\text { Profuse }\end{array}$ & $\begin{array}{r}8 \\
32 \\
8 \\
1\end{array}$ & $\begin{array}{r}16 \\
65 \\
16 \\
2\end{array}$ & $\begin{array}{r}19 \\
55 \\
10 \\
2\end{array}$ & $\begin{array}{r}22 \\
64 \\
12 \\
2\end{array}$ \\
\hline \multirow[t]{2}{*}{ Colour } & $\begin{array}{l}\text { Clear } \\
\text { White } \\
\text { Yellow } \\
\text { No discharge }\end{array}$ & $\begin{array}{r}27 \\
8 \\
6 \\
8\end{array}$ & $\begin{array}{l}55 \\
16 \\
12 \\
16\end{array}$ & $\begin{array}{r}45 \\
15 \\
7 \\
19\end{array}$ & $\begin{array}{r}52 \\
18 \\
8 \\
22\end{array}$ \\
\hline & Total & 49 & & 86 & \\
\hline
\end{tabular}

no history or signs of urethritis; all the specimens were taken with the urethral curette.

The sexual histories of these patients during the 3 months before examination were as follows. Four had not had intercourse at all (although three had previously), ten only with their wives or regular girl friends, and twenty with one or more new contacts.

The following results were obtained:

No. of specimens taken

No. giving Chlamydia isolates

No. giving no isolates

No. contaminated

34
0
31
3

(3) Contacts of men with NSU

41 women were seen who were sexual contacts of the 150 men with NSU. None of these women had gonorrhoea, but four had trichomoniasis and five candidiasis. Urethral and cervical specimens were inoculated on to irradiated McCoy cells, with the following results:

URETHRAL SPECIMENS

No. taken

No. giving Chlamydia isolates $\quad 41$

No. giving no isolates

No. contaminated

CERVICAL SPECIMENS

No. taken

No. giving Chlamydia isolates

No. giving no isolates

No. contaminated

The eight patients from whom urethral isolates were obtained also gave isolates from the cervix; thus in no case were Chlamydia found in the urethra but not in the cervix. Gram-stained urethral smears showed a normal number of polymorphonuclear leucocytes (less than 5 per HPF) in all 41 patients.

When Chlamydia isolation from the men with NSU and from their contacts was compared, the results shown in Table VI were obtained.

TABLE VI Isolation of Chlamydia from men with NSU and their female contacts

\begin{tabular}{lll}
\hline Isolation of Chlamydia & & \\
\cline { 1 - 2 } Man with NSU & Female contact & No. of cases $^{\mathrm{a}}$ \\
\cline { 3 - 3 } Positive & Positive & 12 \\
Positive & Negative & 6 \\
Negative & Positive & 1 \\
Negative & Negative & 22 \\
\hline
\end{tabular}

aPatients with contaminated specimens excluded

Contacts of eighteen men with NSU from whom Chlamydia had been isolated were examined: twelve of these women yielded isolates themselves. In only one case was a Chlamydia isolate obtained from a woman but not from her contact with NSU. In 22 cases, both the man with NSU and the contact gave negative results.

To decide whether a woman was a primary or secondary contact of a man with NSU was not always possible. However, eight women were seen who were thought to be primary contacts of men with Chlamydiapositive NSU; seven gave Chlamydia isolates themselves. On the other hand, only four out of eight secondary contacts of men with Chlamydia-positive NSU gave positive results. There were two cases in which the primary contacts were positive and the secondary contacts negative.

Of the thirteen women from whom Chlamydia isolates were obtained, eight were asymptomatic, 
four complained of vaginal discharge with dysuria in one case, and one complained of pruritus vulvae. None had conjunctivitis or gave a history of recent eye infection. The cervix appeared to be normal to the naked eye in three patients, five had a cervical erosion and two a purulent cervical discharge without erosion. $T$. vaginalis was isolated from two women, both asymptomatic, and C. albicans from the woman who complained of pruritus. Cervical cytology revealed no distinctive changes, the findings in all the women being reported as either Grade A1 or A2.

There were six women from whom Chlamydia was not obtained who were contacts of men with Chlamydia-positive NSU. Four were asymptomatic, one complained of vaginal discharge and vulval irritation, and one of dysuria. None had conjunctivitis or gave a history of recent eye infection. The cervix appeared to be normal in three, one had a cervical erosion, and two a purulent cervical discharge. C. albicans was isolated from two women, one of whom complained of vulval irritation; again, the findings on cervical cytology were reported as either Grade $\mathrm{A} 1$ or $\mathrm{A} 2$.

22 women from whom Chlamydia isolates were not obtained were contacts of Chlamydia-negative men. Sixteen were asymptomatic, three complained of vaginal discharge, and three of dysuria; three were pregnant. None had conjunctivitis, but one gave a history of a recent eye infection. The cervix appeared to be normal in 14 cases, in three there was a cervical erosion, in one Nabothian follicles, and in four a purulent cervical discharge. Two asymptomatic women were found to have $T$. vaginalis and a futher two $C$. albicans. Once more, the cytological findings were Grades A1 and A2, with no distinctive changes.

In summary, there was no noticeable difference in symptoms or clinical findings between those contacts from whom Chlamydia was isolated and those from whom it was not obtained. However, only gross morphological changes in the cervix would have been detected, as colposcopy was not at that time being carried out.

\section{Discussion}

In this study we have attempted to isolate Chlamydia from urethral material obtained from men with first attacks of NSU. Cultures in irradiated McCoy cells yielded Chlamydia isolates, as evidenced by the appearance of characteristic cytoplasmic inclusions, in approximately 37 per cent. of cases. The isolation rate was about the same whether a curette or a swab was used to collect specimens, although contamination was more than twice as common with the swab.
These results are in agreement with those reported by other workers (Dunlop and others, 1971; Richmond, Hilton, and Clarke, 1972).

The recovery of Chlamydia from some patients with NSU does not, of course, establish that in these patients the organisms are responsible for the clinical disease, and we considered the possibility that Chlamydia might be a commensal, perhaps transmitted by sexual contact. To investigate this we examined a control series of men who had attended our Department but in whom urethritis was absent; all specimens from these men were collected with a urethral curette, since in the absence of a discharge little or no material would be recovered with swabs. In no case was a chlamydial agent isolated. There was no evidence from the clinical histories that the men in the control group were less sexually active than those with NSU. Thus, in our experience, not only is Chlamydia found in some men with NSU, but the possibility that the organism is a commonly occurring commensal in the male genital tract can be excluded.

Examination of female contacts of men with first attacks of NSU revealed a similar overall isolation rate. When the distribution of Chlamydia among these women was examined, a striking pattern emerged. The organisms were recovered almost entirely from the female contacts of men in whom positive isolations had also been made. Conversely, if we failed to isolate a chlamydial agent from a man with NSU, his partner was nearly always negative also. Thus, not only was Chlamydia in men apparently confined to those with NSU, but it also appeared to be sexually transmitted. In the relatively small number of cases studied, it appeared that Chlamydia might be more regularly transmitted from primary contacts of men with NSU than to secondary contacts. We were unable to detect any characteristic clinical signs of chlamydial infection in women. However, other workers have described follicles and other changes in the appearance of the cervix which are visible with the colposcope (Dunlop and others, 1964), and we shall be using this instrument in the future.

Although Chlamydia was found in over one-third of men with NSU, the problem remains that in the majority of cases no evidence of chlamydial infection can be found. Clinically, no differences were seen between men with NSU who yielded Chlamydia isolates and those who did not. It is possible that improved methods might raise the isolation rate. We do not know the efficiency of our isolation technique, although the ability to obtain positive results from female contacts of Chlamydia-positive men does suggest that the methods used are relatively effective. It is conceivable that repsated isolation attempts 
from an individual patient might be positive although the first was negative. Evidence for this could not be obtained unless many patients were left untreated while repeated urethral specimens were taken; we did not feel that this could be justified in a potentially infectious disease, so we have not investigated this point. However, refinements in laboratory techniques may be made. Reeve and Taverne (1967) have shown that, with a Gambian trachoma strain (MRC 1 OT), the number of inclusions produced in inoculated cells is directly proportional to the speed of centrifugation of the specimens, and we are considering the use of a high-speed centrifuge in the future.

It seems likely that further studies of men with NSU from whom Chlamydia cannot be recovered will require evidence from other sources to establish whether or not chlamydial infection is involved in these patients. Previous workers have found that the use of the group-reactive lymphogranuloma venereum complement-fixation test (LGVCFT) is unrewarding (Barwell, Dunlop, and Race, 1967). In our experience, only 38 per cent. of sera from men with NSU from whom Chlamydia isolates were obtained gave a titre of 1 in 16 or more with the LGVCFT (Reeve, Oriel, Gerloff, Philip, and Uttley, 1972).

In future studies, we propose to investigate the use of more sensitive serological methods such as immunofluorescent techniques (Hanna, Jawetz, Nabli, Hoshiwara, Ostler, and Dawson, 1972; Collier, Sowa, and Sowa, 1973) and radioimmune precipitation methods (Gerloff and Watson, 1967). Preliminary results with these tests have been promising (Philip, 1972; Reeve and others, 1972).

A major problem in the future will be to devise methods for the assessment of the results of the treatment of chlamydial genital infections with antibiotics. In these patients, chlamydial isolation is unlikely to be successful, yet the disease may still be active and liable to recur. The application of refined cytological techniques, perhaps combined with repeated serological examinations, may prove to be necessary to evaluate a patient's progress.

\section{Summary}

The role of Chlamydia in the causation of nonspecific urethritis (NSU) has been studied by inoculating urethral material from 150 men with first attacks of NSU on to irradiated McCoy cells. Of 98 uncontaminated specimens obtained by urethral curetting, 35 ( 36 per cent.), and of 37 uncontaminated specimens obtained by urethral swabbing, 14 (38 per cent.), yielded Chlamydia isolates. No isolates were obtained from urethral curettings from 34 men without urethritis. It is suggested that a significant proportion of NSU appears to be due to chlamydial infection, and no evidence was found that Chlamydia is merely a commensal in the male genital tract. There was no apparent clinical difference between men with NSU from whom Chlamydia isolates were obtained and those from whom isolates were not obtained.

Urethral and cervical specimens from 41 women who were sexual contacts of the men with NSU were also inoculated on to irradiated McCoy cells. Chlamydia isolates were obtained from thirteen out of 38 uncontaminated cervical specimens and from eight out of 38 uncontaminated urethral specimens. Isolates were obtained from twelve out of eighteen female contacts of Chlamydia-positive men but from only one out of 23 contacts of Chlamydia-negative men. It is concluded that Chlamydia is often sexually transmitted.

Nearly two-thirds of men with NSU show no evidence of chlamydial infection, and possible techniques are discussed for investigating those patients who fail to yield Chlamydia isolates.

We are very grateful to Dr. S. Darougar of the Institute of Ophthalmology, London, for his helpful advice on the method of cell culture. We are also grateful to the Department of Clinical Virology, St. Thomas' Hospital, for providing some of the laboratory facilities. Dr. R. Alper of the Department of Radiopathology (MRC), Royal Postgraduate Medical School, London, and Mr. C. Page of the Physics Laboratory, Radiotherapy Department, St. Thomas' Hospital, kindly undertook the irradiation of our cell cultures. We are also most grateful to Mr. I. A. Williams, F.I.T.V., for much invaluable assistance.

This project was supported by a grant from the Medical Research Council.

\section{References}

Barwell, C. F., Dunlop, E. M. C., and Race, J. W. (1967) Amer. F. Ophthal., 63, 1527

Black, F. T., and Rasmussen, O. G. (1968) Brit. F. vener., Dis., 44, 324

Boyd, J. T., Csonka, G. W., and OAtes, J. K. (1958) Ibid., 34, 40

Collier, L. H. (1960) Rev. int. Trachome, 37, 585

- Sowa, J., and Sowa, S. (1972) F. Hyg. (Lond.), 70, 727

DAROUgaR, S., Kinnison, J. R., and Jones, B. R. (1971) 'Trachoma and Related Disorders', ed. R. L. Nichols, p. 63. Excerpta Medica, Amsterdam

Dunlop, E. M. C., Jones, B. R., and Al-Hussaini, M. K. (1964) Brit. F. vener. Dis., 40, 33 
- Freedman, A., Garland, J. A., Harper, I. A., JONES, B. R., RACE, J. W., DU TOIT, M. S., and Treharne, J. D. (1967) Amer. F. Ophthal., 63, 1073

-, Hare, M. J., Darougar, S., and Jones, B. R. (1971)

'Trachoma and Related Disorders', ed. R. L. Nichols, p. 494. Excerpta Medica, Amsterdam

$\longrightarrow,-,+,-$, and RICE, N. S. C. (1969) f. infect. Dis., 120, 463

FORD, D. K., and MCCANDLISH, L. (1969) Brit. F. vener. Dis., 45, 44

Gerloff, R. K., and Watson, R. O. (1967) Amer. $\mathcal{F}$. Ophthal., 63, 1492

Gordon, F. B., Dressler, H. R., and Quan, A. L. (1967) Ibid., 63, 1044

- and Quan, A. L. (1965) Proc. Soc. exp. Biol. (N.Y.), 118, 354

—, Harper, I. A., Quan, A. L., Treharne, J. D., DWYER, R. St. C., and GARLAND, J. A. (1969) $\mathcal{F}$. infect. Dis., 120, 451

Hanna, L., Jawetz, E., Nabli, B., Hoshiwara, I., Ostler, B., and DAwson, C. (1972) f. Immunol., 108, 102

Hare, M. J., Dunlop, E. M. C., and Taylor-Robinson, D. (1969) Brit. f. vener. Dis., 45, 282

JoNES, B. R., Collier, L. H., and SMITH, C. H. (1959) Lancet, 1, 902

PhILIP, R. N. (1972) Personal communication

Phillips, I., Humphrey, D., Middleton, A., and Nicol, C. S. (1972) Brit. F. vener. Dis., 48, 287

Reeve, P., Oriel, J. D., Gerloff, R. K., Philip, R. N., and Uttley, A. M. C. (1972) In Preparation and TaVkRne, J. (1967) Amer. F. Ophthal., 63, 1167

Richmond, S. J., Hilton, A. L., and Clarke, S. K. R. (1972) Brit. F. vener. Dis., 48, 437

T'ANG, F. F., Chang, H. L., Huang, Y. T., and Wang, K. C. (1957) Chin. med. $\mathcal{~} .$, 75, 429
Infection chlamydiale

Isolement du Chlamydia chez des malades atteints d'affection génitale non spécifique

\section{SOMMAIRE}

Le rôle des Chlamydia dans l'étiologie de l'urétrite non spécifique (UNS) a été étudié en inoculant des cellules McCoy irradiées avec le matériel urétral de 150 hommes présentant une première attaque d'UNS. Des 98 spécimens non contaminés obtenus par curetage urétral, 35 (36 pour cent), et des 37 spécimens obtenus par écouvillonnage urétral, 14 (38 pour cent), permirent d'isoler des Chlamydia. Aucun isolement ne fut obtenu après curetage chez 34 hommes sans urétrite. Ceci suggère qu'une proportion significative d'UNS apparaît être due à une infection chlamydiale et il ne fut pas trouvé de preuve que les Chlamydia sont les commensaux des voies génitales masculines. Il n'y eut pas de différence clinique apparente parmi les hommes atteints d'UNS entre ceux chez qui les Chlamydia avaient été isolés et ceux chez qui il n'en fut pas obtenu.

Des spécimens urétraux et cervicaux de 41 femmes partenaires sexuel les d'hommes atteints d'UNS furent également inoculés dans des cellules McCoy irradiées. L'isolement de Chlamydia fut obtenu pour 13 des 36 spécimens cervicaux non contaminés et pour 8 des 38 spécimens urétraux non contaminés. Des Chlamydia furent isolés chez 12 des 18 contacts féminins d'hommes Chlamydia-positifs, mais seulement chez 1 des 23 contacts des hommes Chlamydia-négatif. On conclut que le Chlamydia est souvent transmis sexuellement.

Presque deux tiers des hommes atteints d'UNS ne montrèrent aucune évidence d'une infection à Chlamydia et l'on discute des techniques possibles pour les recherches à faire chez ces malades pour lesquels il fut impossible d'isoler des Chlamydia. 